\title{
Vernix Caseo Granulomatous Meningitis (Vernicomyelia)
}

\author{
Rajiv Midha and Laurence E. Becker
}

\begin{abstract}
An apneic and tetraplegic infant with an open lumbosacral myelomeningocele and an Amold-Chiari malformation is reviewed. An exuberant chronic aseptic meningitis with foreign body giant cells and immunoreactive keratin was present around the spinal cord and brainstem. This paper discusses the recognition and role of granulomatous meningitis in the clinical course and in the pathogenesis of the unusual cerebellar abnormalities found in this infant.
\end{abstract}

RÉSUMÉ: Méningite granulomateuse à vernix caseosa (vernicomyélie). Nous revoyons le cas d'un nouveau-né apnéique et quadriplégique ayant un myéloméningocèle lombo-sacré ouvert et une malformation d'Arnold-Chiari. Une méningite aseptique chronique exubérante à cellules d'inclusions géantes et kératine immunoréactive était présente autour de la moelle épinière et du tronc cérébral. Cet article discute de l'identification et du rôle de la méningite granulomateuse dans l'évolution clinique et la pathogenèse des anomalies cérébelleuses inusitées trouvées chez ce nourrisson.

Can. J. Neurol. Sci. 1991; 18: 63-65

Vernix caseo granulomatous meningitis is rare in infants with dysraphic conditions ${ }^{1-3}$. This paper reports an unusual case involving an open lumbosacral myelomeningocele, the ArnoldChiari malformation and an intense leptomeningitis secondary to amniotic sac contents around the spinal cord and brainstem.

\section{Case Report}

This baby boy was born at 37 weeks' gestation to a 31 -year-old primigravida mother. The birth followed surgical rupture of the membranes and a vaginal forceps-assisted delivery. Fetal lumbosacral myelomeningocele had been diagnosed by ultrasound scan at 32 weeks' gestation. The fetal karyotype on amniocentesis was normal male, 46 $\mathrm{XY}$. A maternal TORCH screen was negative.

At birth, the baby weighed 3,000 grams. The head circumference was $31 \mathrm{~cm}$. The Apgar scores were 3 and 7 . He was apneic and required immediate intubation and ventilation.

A $1-\mathrm{cm}$ myelomeningocele defect was present in the lumbosacral spine. It was open and had no accompanying sac. The baby was flaccid from the outset. Arm movements were absent and, although there were reports of spontaneous lower extremity movements, the only leg movements obtained were those elicited by direct stimulation. He was otherwise neurologically unresponsive. Computerized tomography (CT) of the head showed decreased attenuation in the regions of the basal ganglia and cerebral white matter. Craniolacunia and an enlarged foramen magnum were consistent with Arnold-Chiari malformation.

The open myelomeningocele was repaired on day one and a small diastometamyelic bone spur was removed. A tight CSF closure was obtained. Postoperatively, the baby remained ventilator-dependent. No spontaneous movements were present.
A CT scan on day three showed increasing ventriculomegaly and some resolution of the decreased attenuation in the region of the deep cerebral white matter and basal ganglia. The baby could not sustain ventilation without respiratory support and on the fifth day, supportive measures were withdrawn with the parents' consent. He died shortly thereafter and an autopsy was performed.

\section{Postmortem Examination}

The only general autopsy abnormality was a nonfixation of the mesentery with the ileocecal region in the left upper quadrant. A surgical incision was seen at the repair of the myelomeningocele. A careful examination revealed no sinus tract over the head, neck or back.

The brain in the fresh state weighed 292.8 grams (normal for age, 358 grams). ${ }^{4}$ There was generalized polygyria. The cerebral cortex, white matter and deep cerebral nuclei appeared grossly normal. Moderate ventriculomegaly was present with an elongated and narrowed but patent cerebral aqueduct. The surface of the brainstem and cerebellum was softened and gray. The cerebellum was grossly malformed. It was hypoplastic and asymmetrical with a small left cerebellar hemisphere, absent right hemisphere and a rudimentary vermis. The pons was hypoplastic and small in relation to the medulla. The cerebellar remnant, dorsal medulla and fourth ventricle were displaced caudally below the foramen magnum with a resulting dorsal kink in the cervicomedullary junction. The dura was tightly adherent to the

From the Division of Neuropathology, Department of Pathology, the University of Toronto, and The Hospital for Sick Children, Toronto Received July 4, 1990. Accepted in final form October 23, 1990

Reprint requests to: Dr. L.E. Becker, Department of Pathology (Neuropathology), The Hospital for Sick Children, 555 University Avenue, Toronto, Ontario, Canada M5G 1 X8 
underlying leptomeninges through an irregular greenish-gray subdural membrane along the entire length of the spinal cord.

Microscopic examination confirmed the presence of a myelomeningocele with distorted cord parenchyma associated with mild hydromyelia in the thoracolumbar spinal cord. An intense inflammatory reaction was present in the subarachnoid and subdural space around the spinal cord and in the leptomeninges around the brainstem and cerebellum (Figure 1). The inflammatory infiltrate was chronic, with lymphocytes, macrophages and foreign body giant cells, and appeared to have developed in response to numerous desquamated squamous cells and keratinous debris, which demonstrated striking positivity by the keratin immunohistochemical method (Figure 2). Gram and fungal stains were negative.

The cerebellar hypoplasia and asymmetry, caudal descent of the cerebellar remnant, dorsal medulla, and open part of the fourth ventricle were confirmed on microscopic examination. The ventral medulla and upper cervical cord appeared compressed and gliotic. The latter was highlighted by the glial fibrillary acidic protein immunostain, which demonstrated an increasing gradient of gliosis in the brain stem which was greatest at the lower medulla and upper cervical junction.

Microscopic examination of the supratentorial structures was unremarkable. The leptomeninges over the cerebrum and the ependymal lining of the ventricles were free of inflammation.

\section{DISCUSSION}

The finding of amniotic sac contents (squamous cells, lanugo hair and mucus) in the spinal subarachnoid space and the spinal cord in infants with an Arnold-Chiari malformation and a lumbar myelomeningocele was first reported by Jacobs et al in 1961.' The keratinous debris was accompanied by a granulomatous foreign body giant cell reaction in the leptomeninges. Jacobs et al" proposed the term "vernicomyelia" for this lesion. In their series, six of 24 infants, all aged three months or less, had vernicomyelia. Hydrocephalus was present in all six affected infants, cerebellar malformation in five, hydromyelia in three

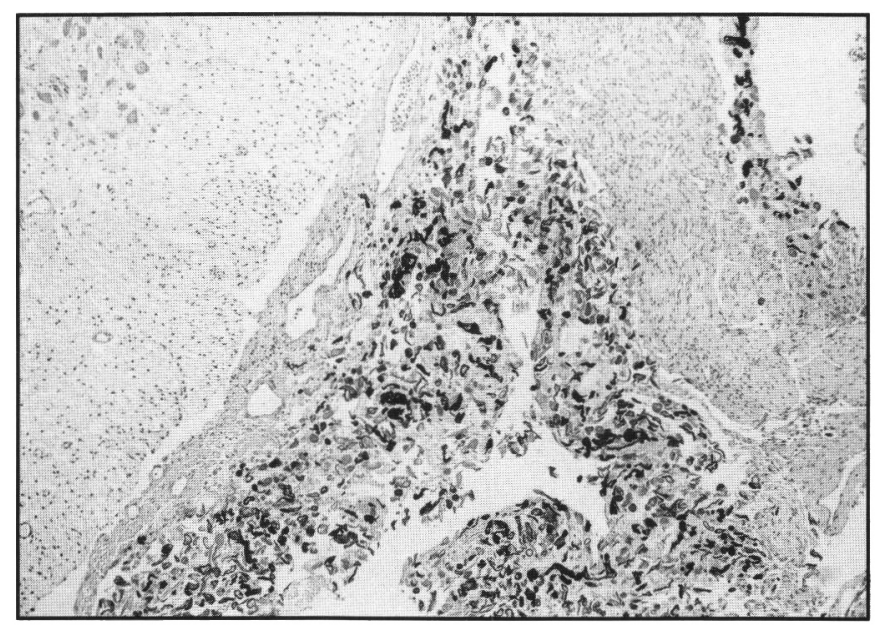

Figure I - Inflammatory reaction in leptomeninges with lymphocytes, macrophages, and foreign body giant cells. Hematoxylin and eosin, $X 400$. and rachischisis in one. The present case also had hydrocephalus, cerebellar malformation and hydromyelia. Jacobs et all did not report extension of the leptomeningitis to the level of the brainstem in any of their six cases.

Correa-Restrepo et al $^{2}$ presented a similar case of an infant with apneic spells, laryngeal stridor and pharyngeal paralysis who succumbed to apneic episodes on the ninth day of life. Their patient had an open lumbar myelomeningocele, marked cerebellar and less severe pontine hypoplasia, hydrocephalus and a vernix caseo granulomatous meningitis around the spinal cord and brain stem. The cerebellar maldevelopment without an Arnold-Chiari malformation in their case and the severe cerebellar abnormality disproportionate to that usually seen in the Amold-Chiari malformation 5 in our case, make it tempting to speculate on the role of direct or indirect vascular ischemic injury in the pathogenesis of the cerebellar lesions by the keratin-induced meningitis around the brainstem and cerebellum.

It is well known that keratin and similar material rich in lipids and cholesterol have an intensely irritating effect on the meninges. Spillage of such contents from lesions containing them, into the subarachnoid space, can result in acute, 6,7 relapsing, 8,9 and chronic meningitis 10 and can cause widespread damage, including necrosis of the nervous system. The latter might be a direct toxic effect of the material or, because of vascular occlusion and infarction, secondary to the chronic granulomatous meningitis. A direct toxic effect of keratin and cholesterol on the brain has been suggested, 11 but remains to be proven. A role for keratin and lipids has also been suspected in the further degeneration of the area cerebrovasculosa, which is bathed by amniotic fluid, in the anencephalic fetus. ${ }^{12}$

The severe cerebellar abnormality seen in our patient may have resulted from the pathogenetic factors usually cited in the Arnold-Chiari malformation, which have recently been reviewed..$^{5}$ In addition, our case raises the possibility of aseptic meningitis, secondary to amniotic sac contents, causing antenatal damage to the developing nervous system in an infant with an Arnold-Chiari malformation and an open myelomeningocele.

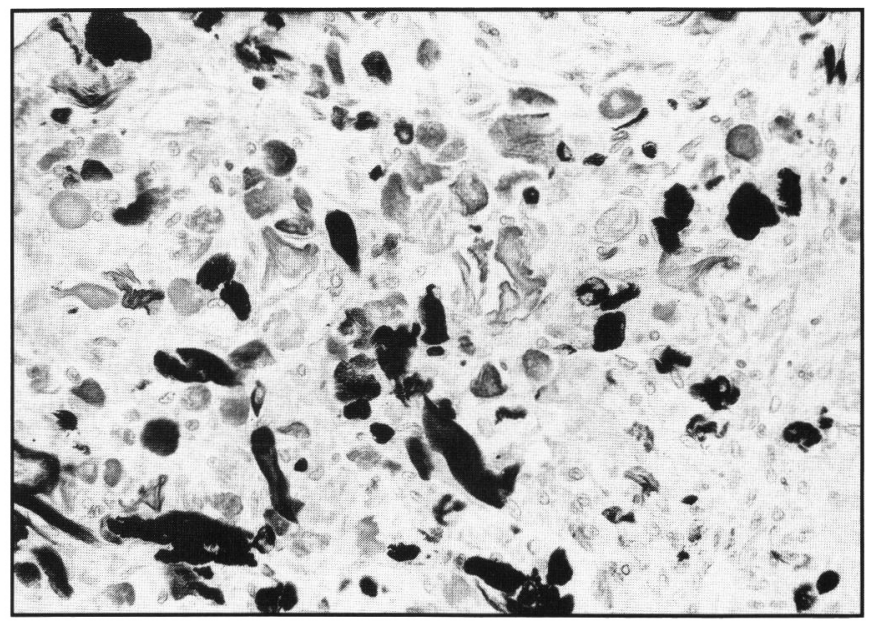

Figure 2 -Desquamated squamous cells showing a positive reaction with antiserum to cytokeratin. Immunoperoxidase, XI60. 


\section{ACKNOWLEDGEMENT}

This paper was prepared with the assistance of Medical Publications, The Hospital for Sick Children, Toronto.

\section{REFERENCES}

1. Jacobs EB, Landing BH, Thomas $\mathrm{W}$ Jr. Vernicomyelia. Its bearing on theories of genesis of the Arnold-Chiari complex. Am J Pathol 1961; 39: 345-353.

2. Correa-Restrepo A, Robertson C, Rozdilsky B. Vernix caseosa meningitis and laryngeal stridor in an infant with myelomeningocele. Case report. J Neurosurg 1975; 42: 718-722.

3. Agamanolis DP, Hite SH, Platt MS. Arnold-Chiari malformation: Contamination of ventricular and subarachnoid spaces by amniotic sac contents (Abstract). Canadian Association Neuropathologists meeting, Ottawa, Canada, 1984.

4. Copoletta JM, Wolbach SB. Body length and organ weights of infants and children. A study of the body length and normal weights of the more important vital organs of the body between birth and twelve years of age. Am J Pathol 1933; 9: 55-70.

5. Friede RL. Forms of hindbrain crowding, including the ArnoldChiari malformation. In: Friede RL, ed. Developmental Neuropathology. Berlin: Springer-Verlag 1989; 2: 263-276.
6. Decker RE, Gross SW. Intraspinal dermoid tumor presenting as chemical meningitis. Report of a case without dermal sinus. J Neurosurg 1967; 27: 60-62.

7. Shimoji T, Shinohara A, Shimizu A, et al. Rathke cleft cysts. Surg Neurol 1984; 21: 295-310.

8. Cantu RC, Wright RL. Aseptic meningitis syndrome with cauda equina epidermoid tumor. J Pediatr 1968; 73: 114-116.

9. Schwartz JF, Balentine JD. Recurrent meningitis due 10 an intracranial epidermoid. Neurology 1978; 28: 124-129.

10. Tomlinson BE, Walton JN. Granulomatous meningitis and diffuse parenchymatous degeneration of the nervous system due to an intracranial epidermoid tumor. J Neurol Neurosurg Psychiatry 1967; 30: 341-348.

11. Horoupian DS, Wisniewski HM, Gamble R, et al. Aqueduct gliosis caused by keratin and cholesterol in a case of craniopharyngioma. Can J Neurol Sci 1974; 1: 185-188.

12. Dickson DW, Neumann PE, Horoupian DS. Immunoreactive keratin with foreign body reaction in anencephaly. Acta Neuropathol (Berl) 1985; 67: 326-328. 